mgement should be given to a class of Irish College of Surgeons, and Dr. Jacob," scientific apothecaries." Inasmuch as their present emoluments were derived principally from their own prescriptions of their own medicine, if a future race were to be prevented from prescribing, the chief source of their subsistence would be withdrawn. Bat then how was encouragement to be given? Why, by incorporating a College of Pharmacy. One of its by-laws would no doubt be that the education and qualification of the candidates for its diploma should be of the very highest order. The public would have the services of a far higher order of pure apothecaries, and the profession would be more limited as to numbers. The apothecaries are too numerous by three-fourths -the quantity of pharmaceutical business is inadequate to support them in comfort and respectability. The College of Pharmacy would no doubt secure to the apothe. caries of Ireland the exclusive sale of medicines, a source of profit at present more in the hands of the grocer than the apothecary. The resolution contemplated the prevention of medical practitioners from compounding the prescriptions of others, but provided for general practitioners compounding their own. The Irish apothecary had been a person who may or may not possess a knowledge of the healing art. He concluded by moving,-

"That encouragement should be given to scientific apothecaries (whose time would be exclusively devoted to the preparation and compounding of medicines), by the es. tablishmeut of a College of Pharmacy; by preventing medical practitioners from keeping shops for the sale of drugs, or compounding the prescriptions of others, and by affording to regularly-educated apothecaries an exclusive right of dealing in medicinal articles."

Seconded by Dr. Kingsley, of Roscrea, and agreed to.

Dr. WALSH, of Tullamore, moved,-"That we disclaim all intention of interfering with vested rights now enjoyed by any individuals."

Dr. Morrison seconded the resolution, which was adopted.

Dr.TAbuteau moved, "That the establishment of a relief and widows' fund be recommended to the Provisional Council." to.

Seconded by Sir A. Clarke, and agreed

The best thanks of the meeting were then given to Mr. Carmichael, the Chairman.

In the evening the principal delegates and friends dined together at Radley's Hotel, Commercial - buildings, Mr. Carmichael being President.

The cloth being remored, the following toasts were drunk:-"The Queen," "The Lord Lientenant," "The Medical Union of Ireland," " Richard Carmichael," "The 'The Infirmary, Dispensary, and Army Surgeons, of Ireland," "The Physicians of Ireland," "The Medical Press," "The Western Medical Society, the oldest in Ireland," "The Provincial Medical Associations," and "The Stewards."

At twelve o'clock the party broke up, after an evening of undisturbed harmony.

On the following Friday, the President and Council of the Association waited on the Lord Lieutenunt, to lay before him the resolutions adopted at the Congress, and to pray his consideration of them. His Excellency entered into the subject with interest. He was informed that it was not the object of the deputation to press for a reply to any request, but partly to anticipate any statements which might be made respecting the objects of the meeting by persons who did not coincide in its views. After a long conversation, the deputation retired, much gratified at their reception.

\title{
A CASE OF
}

\section{N T U S - S U S C E P T I O,}

WITH SEPARATION OF FIVE INCHES OF INTESTINE, FOLLOWED BY COMPLETE RECOVERY.

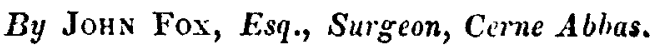

Henry Diment, at. 16, residing in the parish of Nether Cerne, was taken ill on the morning of MIonday, September the loth. I first saw him at four in the afternoon. On inquiry, I found he had felt a little uneasiness in his bowels on the preceding day, with a slight sense of chilliness, and bad taken a little milk and water, with a small quantity of bread in it, instead of his usual more substantial breakfast; that he had eaten some nuts on the 8 th, but had, prior to the 9 th, enjoyed an excellent state of health. He bad passed a restless night, and had suffered from dull pain about the navel for a minute or two several times in an hour; had taken several ounces of castor oil without effect; bowels had not been opened for 24 hours. The tongue was slightly coated, but moist; he had no thirst; pulse 32 , soft, and a little irregular; shin natural; urine of pale straw colour, and passed without inconvenience. The abdomen appeared somewhat tumid, but the pain, which he described as a "dull, griping pain," was diminished by steady pressure. I prescribed five grains of calomel and one grain of opium, to be taken immediately, and half an ounce of castor oil every four hours, until the bowels had been freely opened.

Sept. 11th, seven A.M.-He has passed a sleepless, restless night; the same kind of pain continues about the umbilicus, dot in. creased on pressure; thirst more urgent; has rejected every dose of the oil; pulse 96, small and intermitting, but soft and 
easily compressible; skin rather perspiring; tongue moist and white; urine natural; no anxiety of countenance; slight fulness of abdomen;-to take two grains of calomel, and eight of compound extract of colocynth, every four hours, until relieved, and with each dose of the pills a saline aperient in a state of effervescence, and if the pain and constipation continued, to be put into a hot bath for twenty minutes in the afternoon.

Eight P.M. Worse; skin hot; pulse 102, intermits every six or seren beats; face slightly flushed, but countenance not anxious; medicine and everything else taken during the day immediately rejected; was free from pain whilst in the bath, and dozed a little for half an hour afterwards. I examined the abdomen again; it was not more tumid; and I could not detect any unnatural fulness in any part, but firm pressure around the navel produced uneasiness; the pain had been constant for several hours, but more violent at intervals; there was no hernia; twelve leeches were ordered to the abdomen, to be followed by warm fomentations with scalded bran; a common purgative injection to be administered, and the hot bath to be repeated if necessary; and a pill containing one drop of croton oil every two hours.

12. He has passed a sleepless night; pain almost constant, and very severe at intervals; slight pain is also felt on pressure over the epigastrium; sickness continues; everything taken immediately rejected; belly rather more tumid; it appears somewhat fuller and harder about the centre of the right iliac region than on the opposite side; pulse 104, small, but soft, intermits every fourth or fifth stroke; urine rather scanty, otherwise natural ; skin hot ; tongue white, but moist, and there is little thirst; a blister, containing two grains of muriate of morphia, ordered to the epigastrium; the hot bath and injection to be repeated, as well as the pills, should the stomach be more disposed to retain them; a little soda water to be also given.

13. The hot bath had been used twice during the preceding day and night, with temporary relief to his sufferings; several injections had also been given, but they had been retained a few minutes only, and then returned unstained with feculeut matter. The blister, with the morphia, appeared to have had a very beneficial effect on the stomach, as there had been much less vomiting, and six of the pills had been retained. The night, however, was one of great suffering, and the pain had gradually increased during the last six hours; at seven this morning he had severe bilious romiting; the skin was of a more pungent heat; the tongue very white, but still moist; the thirst more urgent; the face flushed, and for the first time there was an expression of anxiety; the eye was bright, with dilated pupil; the belly more tumid; the pain also now much increased on pressure, and most severe about midway between the umbilicus and spine of right ilium; pulse 116, small, irregular, and somewhat sharp. Bleeding to faintness was performed with immediate relief; bath again ordered if the pain returned.

Calomel, five grains;

Comp. ext. of colocynth, five grains;

Opium, half a grain; every third hour, and if the bowels are not moved, an injection with spt. terebinth. to be administered in the evening. I now came to the conclusion that $I$ had a case of intus-susceptio to deal with.

14. Has passed a more quiet night, with a little sleep, and appears to be under the influence of the opium; the vomiting, however, continues if any fluid be taken, even to the extent of a teaspoonful; the bowels Lave not been moved, are slightly tympanitic ; pain less acute, but constant ; the skin hot, with disposition to be moist; tongue moist and less coated; injection retained a few minutes only; pulse 122, irregular, small, and weak; pills, with calomel, colocynth, and opium, to be continued; if the pain increases, hot bath and fomentations to be repeated.

15. Has dozed a little during the night, but has never been free from pain; four doses of the pills have been retained; face a little flushed; countenance looks sunk, but decidedly less anxious ; tongue clean and moist ; skin burning hot and dry; pulse 136, very irregular, and small ; occasional bilious vomiting, and is afraid to take more than a teaspoonful of fluid at a time, as it produces immediate vomiting; belly slightly tympanitic, and generally tender on pressure; the pills to be continued, and a liniment, with the potass. tart. antimon., to be rubbed in to the abdomen every four hours; if pain increases, an injection, with two drachms of liq. opii. sedativ., to be thrown up, and in the mean time from two to three quarts of thin gruel to be forcibly injected.

16 , seven A.M. Has passed a night of constant pain and vomiting, and bad been wan. dering a good deal at times. I found him on the floor, resting on his knees and elbows, with a bason between his arms containing a large quantity of foeculent matter, and one large lumbricus; everything had been rejected, and he now complains more of the " dreadful sickness"than of the pain. The pulse was 140, irregular, and very small; skin dry and burning hot; tongue clean but dry; belly tumid as before, less pain on pressure; urine scanty, otherwise natural ; countenance looking pinched and haggard; says he feels a little drowsy and confused. The opiate injection was given during the night, but returned immediately. Two minims of acid hydrocyan(Scheele's strength) 
were directed to be taken every hour if the sickness continued.

Eight, P.M. Six doses of the hydrocyanic acid have been taken; the sickness is a little diminished, but still very distressing at times; eyes and countenance still more sunk; tongue dry and brownish; skin dry and burning hot; pulse 145, irregular, and small; belly tumid, but bears pressure better; had felt chilly for a few minutes during the day. It now occurred to me to give inflation a trial, but I certainly did not anticipate any good result from it, as the remedy came so late, and the case appeared so desperate; however, I thought it my duty, and $I$ therefore immediately procured a bladder, and secured one end of it to the nossle of a pair of bellows, and the other end to a common enema pipe, and having introdnced the pipe its full length into the rectum, the bellows were set in motion by my pupil, and inflation forcibly but slowly persevered in for many minutes, until the poor boy complained of a disposition to " break wind," and said that his "belly was very tight." The convolutions of the intestines could be seen and felt distinctly, the arch of the colon most so; the tube was now withdrawn, and, to my great surprise and gratification, in about twenty minutes he said he felt as if he should soon have a stool; he was therefore lifted and supported upon the bed-pan, when he passed off wind in large quantities, which in a few minutes was followed by a very copious and liquid evacuation, containing, however, a few hard lumps. From this time the sickness ceased, and he expressed himself as being much relieved. A little soda-water and milk was allowed.

17. Has passed a tolerably quiet night, dozing at intervals; no sickness; perfectly collected; has had six more copious stools; tongue still dry and brown; pulse 118, very small, but more regular; abdomen tympanitic to a great degree; slight pain, on pressure, between the umbilicus and right ilium; enjoys the soda-water and milk; to have a little biscuit soaked in warm milk and water or tea, and to take a draught, with infus. of rhei and comp. tinct. of card., im. mediately.

18. Improving in every respect. Has passed an enormous quantity of flatus, and several copious evacuations; buwels less tympanitic; edges of tongue moist; pulse 110, soft, and free from intermission. A cup of weak chicken-broth allowed.

19, 20, 21. Has continued to improve slowly; the pain, on pressure, has daily lessened; bowels still tympanitic, have been freely opened, the stools are much too pale; the tongue still dry in the centre; the skin dry and hot, with pulse 104 ; has taken bis aperient daily; the dranght ordared to be repeated every morning, and to take the two following pills at bedtime, viz.,
Blue pill, five grains ;

Comp. ext. of colocynth, three grains;

Ext. of poppy, one grain ; two pills.

22. In the afternoon he was decidedly worse, notwithstanding the bowels had been freely moved, and the evacuations were healthy; the pain on pressure, too, was much less, but the pulse again mounted to 120 , and was small and somewhat irregular without intermission; the tongue was dry, and the thirst urgent; the skin also hot and dry; his expression was anxious, and his present irritability formed a strong contrast to his hitherto calm and patient resignation. A saline draught, with tinct, of digitalis and tinct. of hyoscyam., was ordered to be taken every four or five hours, and I left him with a promise to see him again early the following morning, but at the same time with a firm impression on my mind that the case would even now prove fatal.

23. On my arrival this morning I was much gratified and surprised to hear that about six hours after I left last evening my patient's bowels had been very copiously moved, that be afterwards slept for nearly two hours, and that he expressed himself as feeling in every respect more comfortable ; at the same time, however, his nurse told me she "supposed he would not last many days longer, as a large piece of his bowels had come away with one of his stools." I immediately examined the stool, removed the substance alluded to, and having care. fully washed it, I found that the woman's suspicions were correct, and that it was indeed a portion of one of the intestines, with some of the mesentery still adhering. On visiting my patient I found his nurse's statement correct; he was in every respect more comfortable, although the skin was still hot and dry, and the pulse 112.

From this time the treatment consisted of mild aperients, with a gradual improved diet, and at the end of a fortnight, he had gained flesh and strength sufficient to enable him to remain up for several hours during the day, although the bowels remained slightly tympanitic, and a little pain was still felt on firm pressure. At the end of another fortnight he was able to walk about, and, with the exception of being somewhat paler than before, appeared in excellent health.

It is now nearly four months since his illness, and he continues in perfect health, the bowels acting regularly. He follows his usual occupation of milking, exercising horses, \&c., without inconvenience.-From "he "T $T_{1}$ insactions of the Prov. Med. and Surg. Assoc.," Vol, VII. 


\section{STATISTICS}

or

\section{PULAIONARY CONSUMPTION IN ITALY.}

\section{LEGHORN.}

Civil and Military Hospitals, 1833 to 1835 . PHTHIsis.

Males ......... 54 Deaths ........ 23

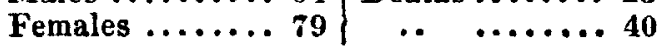

133

The mean number of deaths from phthisis in the Civil and Military Hospitals of Leghorn being 63 , and the general mortality being 678 , it results that the deaths from consumption are to those from all other diseases, as one to ten and threequarters.

\section{FLORENCE.}

Hospital of St. Maria Novella, 1836 to 1837.

Males ....... 3433 Deaths ..... 519

\begin{tabular}{l|ccc} 
Females ....... 3121 & $\ldots$ & $\ldots \ldots$ & 502
\end{tabular}

\section{4}

PHTHISIS.

Males ........ 109 Deaths ........46

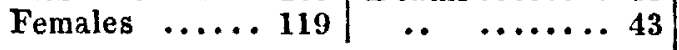

$\overline{228}$

The relative mortality of phthisis, and all other diseases in this hospital, was hence as one to eleven and a half.

\section{ROME.}

Hospital of St. John.

Admitted ...... 2540 | Dead....... 379 PHTHISIS.

Admitted ...... 126| Dead........ 110

From which it would appear that the mortality of phthisis is as one to three and twofifths of all other diseases.

\section{NAPLES.}

Average of three Hospitals.

Admissions, Male .. 3930 Deaths.... 935

$\begin{array}{lllll}. . & \text { Female 2278 } & \ldots & \ldots & 693\end{array}$

$\overline{6208} \quad \overline{1628}$

PHTHISIS.

Admissions, Male..556 Deaths .... 369 \begin{tabular}{lllll}
.. & Female 434 & $\ldots$ & $\ldots$. & 320 \\
\hline
\end{tabular}

$\overline{990} \quad \overline{695}$

Hence the mortality of consumption is here as one to two and one-third.

In the military hospitals the mortality of phthisis to that of other diseases was as one to three and six-sevenths.

It results from an examination of these tables that the mortality of pulmonary con- sumption is not very high, either at Florence or livourne; while, on the contrary, at Rome and Naples it amounts to one in three and two-fifths and two and one-third.

On comparing the documents from which the above general results have been drawn, with returns furnished from the French hos. pitals, we obtain the following data for comparison :-

\section{LA CHARITÉ. 1835 to 1836.}

Deaths ............... 707

Deaths from phthisis .......2 216

Here, theu, the mortality of phthisis to that of all other diseases is as one to three and one-fourth.

\section{HOPITAL NECKER.}

1834 to 1836.

Admitted .....2 2304 | Died .....2 241 PHTHISIs.

Admitted....... 136 | Died ....... s1

Proportion of deaths from phthisis one to three.

Admitted..... 7509 | Died ...... 329

Deaths from phthisis............ 27

Proportion of the mortality from phthisis to the general mortality of the Military Hospital, one to twelve and one-fifth.

If we compare the mortality from pulmonary consumption in the Civil and Military Hospitals of Naples and Paris, we shall find that the proportion is very much in favour of the latter city.

\section{CIVIL HOSPITALS.}

Naples, one in two and one-third ; Paris, one in three and one-fourth.

\section{MILITARY HOSPITALS.}

Naples, one in three and six-sevenths; Paris, one in twelve and one-fiftb. - Bullet. de l'Acad. de Med., April, 1839.

INQUEST AT MANCHESTER.

To the Editor of THE LANCET.

SIR :-As my character has been assailed in your last week's periodical, you will oblige me by publishing this reply. I am your obedient servant,

Staly-bridge, June 13, 1839 .

M. D. Thompson.

I have thought it incumbent on me to reply to a slanderous and infamous report (as my character has been assailed in it) of a coroner's inquest (relative to a supposed case of infanticide and concealment of $b$ ir th), held before John Hollins, Esq., and a 